\title{
Infantile desmoplastic astrocytoma: Magnetic resonance imaging suggestive of pathology
}

Sir,

Infantile desmoplastic astrocytoma (IDA) was described by Taratuto et al. ${ }^{[1]}$ in 1984. Two histological forms have been described, one is desmoplastic infantile astrocytoma and other is desmoplastic infantile ganglioglioma (DIG). ${ }^{[1,2]}$ DIG differs in having a neuronal component. Both are rare childhood tumors involving superficial cerebral cortex and leptomeninges. Most cases of DIG/DIA occur in infants between 1 and 24 months with a male:female ratio of 1.7:1.0. ${ }^{[3]}$ Several noninfantile IDA reported with the oldest being 19 years of age. Mostly on presentation it is an enlarging head circumference with tense bulging fontanelles. Typically the tumor is large and cystic with a small enhancing solid cortical component. Superficially, the tumor is extracerebral, involving leptomeninges, and superficial cortex with attachment to the dura. Most of the reported cases are hemispheric. Edema is usually absent and tumor involves preferentially the frontal and parietal lobes. ${ }^{[4]}$ These tumors have a good prognosis and behave in a relatively benign fashion with disease-free survival.

On computed tomography (CT) scan, the cystic portion is hypoattenuating. Calcification is not a feature of DIG. The cystic portion is usually located deep inside the lesion whereas the solid portion is peripheral. ${ }^{[4]}$ The solid portion of these large masses is typically slightly hyperattenuating and typically located along the cortical margin of the mass. Following administration of contrast, these masses usually enhance intensely and may demonstrate a dural tail. On magnetic resonance imaging (MRI), the solid portions typically have the following signal intensity. T1-weighted - isointense to brain parenchyma. T2-weighted - isointense to heterogeneous brain parenchyma. T1-weighted $\mathrm{C}+$ (Gadolinium) intense enhancement dural tail may be seen. The cystic portions typically have the following signal intensity T1-weighted - hypointense and T2-weighted - hyperintense.

A 1-year-old child was admitted with the chief complaints of enlarging head circumference with tense fontanelles. He had a normal cry with

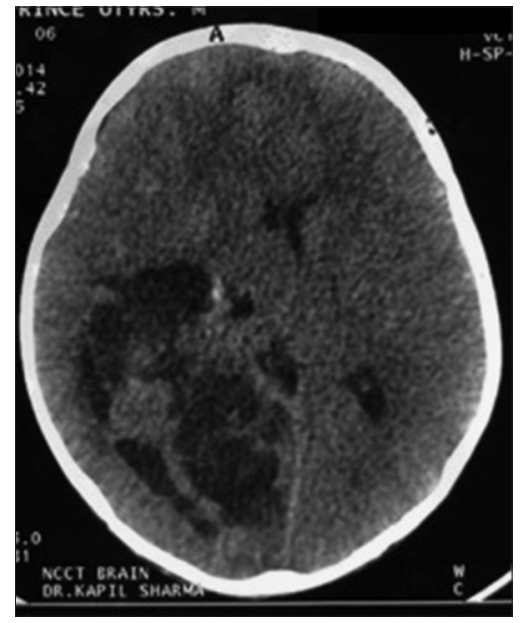

Figure 1: Axial computed tomography scan of the brain

good sucking reflex. The child was investigated radiologically and $\mathrm{CT}$ scan showed mixed density predominantly cystic lesion with no calcific foci A in the right occipitoparietal lobes [Figure 1]. T1-weighted and T2-weighted and postcontrast T1-weighted MRI images showed cystic components appearing hypointense on T1-weighted and intensely hyperintense on T2-weighted scans. Few septations were also seen in the cystic area. Solid components were isointense on T1-weighted and isointense to intermediate intensity on T2-weighted scans [Figure 2]. There was mass effect on the occipital horn and posterior body of the right lateral ventricle with contralateral midline shift. The patient underwent tumor resection and the final histological diagnosis was IDA WHO Grade 1. Glial fibrillary acidic protein, vimentin, and S100 were positive in the tumor cells. Neurofilament (NF) was focal positive in the tumor cells. P53, synaptophysin, and CD34 were negative [Figure 3]. KI 67/MB was approximately $0 \%$. Hence, it was concluded that radiological features were highly suggestive of diagnosis and helpful in preoperative diagnosis and prognosis. Unfamiliarity with these lesions may result in unnecessary chemotherapy and radiotherapy.

\section{Financial support and sponsorship \\ Nil.}




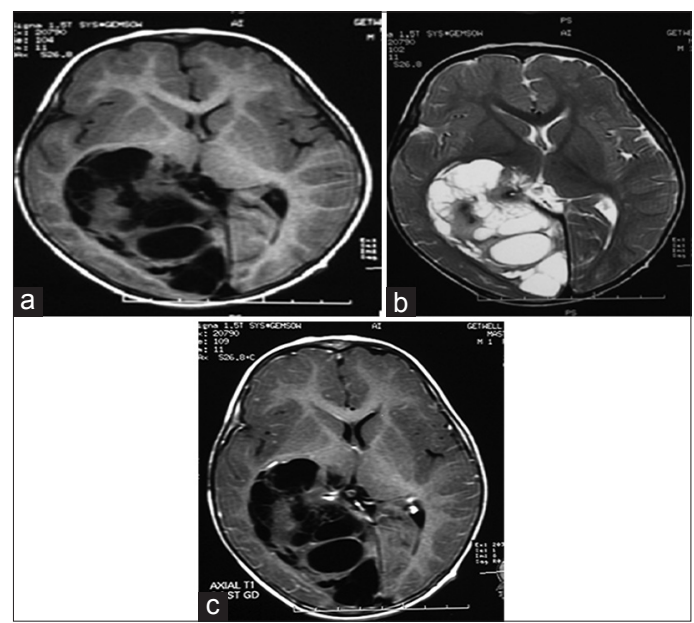

Figure 2: (a) Axial T1-weighted magnetic resonance imaging brain, (b) axial T2-weighted magnetic resonance imaging brain, (c) contrast axial magnetic resonance imaging brain. (a-c) T1-weighted, T2-weighted and post contrast T1-weighted magnetic resonance imaging images shows cystic components appearing hypointense on T1-weighted and intensely hyperintense on T2-weighted scans. Few septations were also seen in cystic area. Solid components are iso intense on T1-weighted and iso to intermediate intense on T2-weighted scans
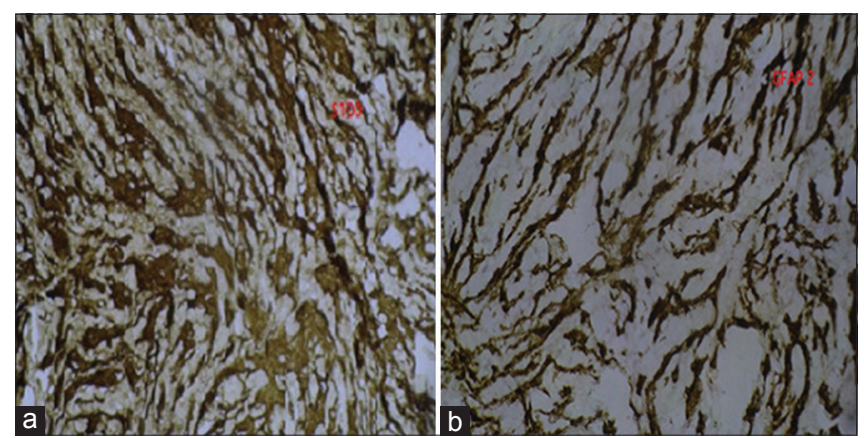

Figure 3: Glial fibrillary acid protein 2, ( $a$ and $b$ ) glial fibrillary acidic protein, vimentin, and $\mathrm{S} 100$ were positive in the tumor cells. NF was focal positive in the tumor cells. P53, synaptophysin, and CD34 were negative. KI 67/MB was approximately $0 \%$ (b) S100

\section{Conflicts of interest}

There are no conflicts of interest.
Bandhul Tiwari, Virendra Deo Sinha, Shashi Singhvi ${ }^{1}$, Anu Bhandari ${ }^{2}$

Departments of Neurosurgery, ${ }^{1}$ Pathology and ${ }^{2}$ Radiodiagnosis, SMS Medical College, Jaipur,

Rajasthan, India

Address for correspondence: Dr. Bandhul Tiwari,

Department of Neurosurgery, SMS Medical College, Jaipur, Rajasthan, India.

E-mail: bandhultiwari90@gmail.com

\section{References}

1. Taratuto AL, Monges J, Lylyk P, Leiguarda R. Superficial cerebral astrocytoma attached to dura. Report of six cases in infants. Cancer 1984;54:2505-12.

2. VandenBerg SR, May EE, Rubinstein LJ, Herman MM, Perentes E, Vinores SA, et al. Desmoplastic supratentorial neuroepithelial tumors of infancy with divergent differentiation potential ("desmoplastic infantile gangliogliomas"). Report on 11 cases of a distinctive embryonal tumor with favorable prognosis. J Neurosurg 1987;66:58-71.

3. Rypens F, Esteban MJ, Lellouch-Tubiana A, Bastien-Fagnou C, Renier D, Baraton J, et al. Desmoplastic supratentorial neuroepithelial tumours of childhood: Imaging in 5 patients. Neuroradiology 1996;38 Suppl 1:S165-8.

4. Taratuto AL, Vandenberg SR, Rorke LB. Desmoplastic infantile astrocytoma and ganglioglioma. In: Kleihues P, Cavenee WK, editors. Pathology and Genetics of Tumour of the Nervous System. Lyon, France: IARC Press; 2000. p. 99-102.

This is an open access article distributed under the terms of the Creative Commons Attribution-NonCommercial-ShareAlike 3.0 License, which allows others to remix, tweak, and build upon the work non-commercially, as long as the author is credited and the new creations are licensed under the identical terms.

\begin{tabular}{|l|l|}
\hline \multicolumn{2}{|c|}{ Access this article online } \\
\hline Quick Response Code: & Website: \\
\hline & www.ruralneuropractice.com \\
\cline { 2 - 3 } & \\
\hline
\end{tabular}

How to cite this article: Tiwari B, Sinha VD, Singhvi S, Bhandari A. Infantile desmoplastic astrocytoma: Magnetic resonance imaging suggestive of pathology. J Neurosci Rural Pract 2016;7:458-9. 